\title{
EL SISTEMA JURÍDICO DE LOS PUEBLOS INDÍGENAS: UNA FORMA DE HACER JUSTICIA*
}

\author{
THE LEGAL SYSTEM OF INDIGENOUS PEOPLES: A WAY \\ OF DOING JUSTICE
}

\section{Tania GONZÁLEZ KAZÉN**}

RESUMEN: El presente artículo surge con el propósito de visibilizar un derecho poco explorado: el de los pueblos indígenas en México a mantener y desarrollar sus propios sistemas jurídicos conforme a su propia cosmovisión, costumbres e identidad cultural. El cual se encuentra protegido por los derechos constitucionales y convencionales a la autonomía y a la libre determinación. He de advertir que no es mi intención agotar con las siguientes reflexiones la amplitud y diversidad de la presente temática, pues sería imposible llevar a cabo dicha tarea. Por lo tanto, mi objetivo primordial será abrir el debate y el diálogo sobre un derecho que, a mi parecer, considero esencial para que los pueblos indígenas puedan mantener su forma de vida.

Palabras clave: pueblos indígenas; derechos humanos; sistemas jurídicos indígenas; derecho a la libre determinación; derecho a la autonomía; debido proceso; interculturalidad.
ABSTRACT: This article has the purpose of making visible a not much explored issue: the right of indigenous peoples in Mexico to maintain and develop their own legal systems according to their own worldview, customs, traditions and cultural identity. Which is protected by the constitutional and conventional rights to autonomy and self determination. I must make a disclaimer that it is not the intention of this article to exhaust the breadth and diversity of this subject with the following reflections, since it would be impossible to carry out such a task. Therefore, my primary objective will be to open debate and dialogue on a right that, in my opinion, is considered essential for indigenous peoples to be able to maintain their way of life.

Key Words: indigenous peoples; human rights; indigenous legal systems; right to self-determination; right to autonomy, due process; interculturality.

* Recibido el 31 de mayo de 2019; aprobado el 17 de agosto de 2020.

* Estudiante de la Facultad de Derecho de la Universidad Nacional Autónoma de México. Actualmente se desempeña como integrante del Observatorio del Sistema Interamericano de Derechos Humanos del Instituto de Investigaciones Jurídicas de la UNAM. Correo electrónico: taniagk98@gmail.com.

Boletín Mexicano de Derecho Comparado, nueva serie, año LII, núm. 158, mayo-agosto de 2020, pp. 619-650 
SUMARIO: I. Introducción. II. Situación actual de los pueblos indígenas en México. III. Autonomía, libre determibación y sistemas jurídicos indígenas en México. IV. El artículo 20. constitucional: hacia el diálogo intercultural. V. El debido proceso del sistema jurídico estatal y características de los sistemas jurídicos indígenas en México. VI. Sistemas jurídicos indígenas en materia penal: crítica al Código

Nacional de Procedimientos Penales. VII. Conclusiones. VIII. Bibliografia.

\section{INTRODUCGIÓN}

Para abordar la temática tan diversa y amplia que es el derecho de los pueblos indígenas a desarrollar y mantener sus propios sistemas jurídicos, primero me dedicaré a describir de forma breve la evolución jurídica que se ha desarrollado en las últimas décadas para reconocer formalmente este derecho en la legislación del Estado mexicano, y desde una perspectiva crítica, analizaré si realmente es efectiva o si dificulta su efectivo goce y ejercicio. Posteriormente, hablaré sobre los diálogos interculturales y la oportunidad que representan para resolver conflictos que surjan entre los sistemas jurídicos indígenas y el sistema jurídico estatal.

Asimismo, para lograr un acercamiento mayor a la temática, realizaré una breve descripción de las características de algunos sistemas jurídicos indígenas en México, los cuales se construyen a partir de su forma particular de ver el mundo y de sus propios sistemas de valores. Lo anterior con la finalidad de demostrar y recalcar que deben ser respetados en un Estado pluricultural.

Por último, analizaré algunas de las restricciones impuestas a los sistemas jurídicos indígenas en materia penal, las diversas lagunas jurídicas que dificultan su ejercicio y las circunstancias poco adecuadas a las que se ven sometidas las personas indígenas cuando se ven obligadas a utilizar el sistema jurídico estatal.

\section{Situación AGTUAL DE LOS PUEBLOS INDíGENAS EN MÉXICO}

El Estado mexicano es rico de una diversidad cultural y social, en donde los pueblos indígenas ${ }^{1}$ ocupan un lugar fundamental. En la actualidad

\footnotetext{
1 Es necesario recalcar que no hay como tal una definición estricta y cerrada de "pueblos indígenas" con el fin de respetar la inmensa diversidad de pueblos indígenas que viven 
existen 68 pueblos indígenas y aproximadamente 25 millones de personas que se identifican a sí mismas como tales (Atlas de los pueblos Indígenas en México 2020), formando el 21\% de la población (Consejo de los Derechos Humanos de las Naciones Unidas 2018, 4; en adelante CDHNU) que, desde tiempos históricos, han considerado a México su hogar y así lo han podido conservar a pesar de la discriminación, aislamiento y despojo que han enfrentado a lo largo del tiempo ( $c f r$. Oficina del Alto Comisionado de las Naciones Unidas para los Derechos Humanos en México 2008, 17; en adelante OACNUDH México; CDHNU 215, párrafo 41).

Los motivos que han dado origen a dicho contexto son varios, pero uno de los más significativos, ha sido la falta de representación de las personas indígenas en la redacción de las constituciones políticas federales que anteceden a la que nos rige en la actualidad, provocando que sus circunstancias, necesidades y derechos humanos fueran invisibilizados (véase Aragón y Color 2013, 487).

Fue hasta 1992 cuando se reconoció por primera vez en la Constitución Política de los Estados Unidos Mexicanos (en adelante CPEUM) que los pueblos indígenas eran parte fundamental e integrante de la nación (cfr. Aragón 2007, 208). Sin embargo, la política que adoptó el gobierno mexicano apostó más bien a la asimilación ${ }^{2}$ de los pueblos indígenas en lugar de a su autonomía, lo que generó que tal "reconocimiento" no fuera adecuado (CDHNU 2017, 4 y 12).

En años posteriores, a raíz del surgimiento del Movimiento Zapatista de Liberación Nacional, se ejerció presión sobre el Estado para que pres-

y existen en el mundo. Sin embargo, para efectos del presente artículo, se entenderá por pueblo indígena lo establecido por el artículo 2o. de la Constitución Política de los Estados Unidos Mexicanos: "Aquellos que descienden de poblaciones que habitaban en el territorio actual del país al iniciarse la colonización y que conservan sus propias instituciones sociales, económicas, culturales y políticas, o parte de ellas", y por el Convenio 169 de la Organización Internacional del Trabajo: "Son indígenas por el hecho de descender de poblaciones que habitaban en el país o en una región geográfica a la que pertenece el país en la época de la conquista o la colonización o del establecimiento de las actuales fronteras estatales y que, cualquiera que sea su situación jurídica, conservan todas sus propias instituciones sociales, económicas, culturales y políticas, o parte de ellas".

2 La asimilación consiste en la adopción de políticas o medidas que tienen por objetivo impedir que los pueblos indígenas desarrollen y mantengan libremente su identidad cultural. Por lo tanto, ésta es una práctica prohibida para los Estados en el Derecho Internacional de Derechos Humanos, ya que provoca la destrucción a su forma de vida ( $\mathrm{c} f \mathrm{r}$. Organización de Estados Americanos 2016, artículo 10). 
tara atención a la situación tan desigual que vivían las personas indígenas (CDHNU 2003, párrafo 11). Esto logró un impacto mayúsculo que impulsó la reforma al artículo 2o. constitucional, publicada el 14 de agosto de 2001, en la que se reconoció a México como un Estado pluricultural y situó a la autonomía de los pueblos indígenas como la base fundamental de una variedad de derechos, entre ellos, el de mantener y desarrollar sus propios sistemas jurídicos (CPEUM, artículo 2o., inciso a, fracción II).

Por otro lado, es preciso mencionar lo que han aportado los instrumentos $^{3}$ y resoluciones de organismos e instancias internacionales ${ }^{4}$ al establecer las obligaciones que los Estados deben cumplir para proteger y garantizar los derechos de los pueblos indígenas, cuyo presupuesto fundamental para su desarrollo y supervivencia radica en respetar su libre determinación y autonomía (Consejo Económico y Social de las Naciones Unidas 2010, párrafo 11, en adelante ECOSOC).

Así, algunos de los derechos protegidos internacionalmente son: a la igualdad y no discriminación; personalidad jurídica; identidad cultural; libre determinación; defensa adecuada y recurso judicial conforme a sus especificidades culturales; protección de sus territorios y recursos naturales; consulta y consentimiento frente a cualquier acción que afecte sus intereses; mantener, desarrollar y controlar sus propias instituciones y formas de justicia, entre otros (Suprema Corte de Justicia de la Nación 2013, 27-38, en adelante SCJN).

Es en este sentido que se puede vislumbrar un progreso en la protección y reconocimiento de los derechos de los pueblos indígenas, pues al reconocerse no sólo en la CPEUM, sino también en el derecho internacional, idealmente deberían manifestarse y garantizarse en la realidad.

Sin embargo, sus diversas culturas y formas de vida siguen considerándose inferiores a la cultura hegemónica occidental, por lo que aún

3 Por ejemplo: Pacto Internacional de Derechos Civiles y Políticos, Pacto Internacional de Derechos Económicos, Sociales y Culturales, Convenio 169 de la OIT, Convención Americana de Derechos Humanos, Declaración de las Naciones Unidas sobre Derechos de los Pueblos Indígenas y Declaración Americana sobre los Derechos de los Pueblos Indígenas.

4 Por ejemplo: el Sistema Interamericano de Derechos Humanos; informes emitidos por organismos de la ONU, como: la Oficina del Alto Comisionado para los Derechos Humanos, la Comisión de Derechos Humanos, la Relatora Especial sobre los Derechos de los Pueblos Indígenas, el Comité de Derechos Económicos, Sociales y Culturales, el Comité de Derechos Civiles y Políticos, entre otros. 
existe una constante subordinación. Asimismo, todavía prevalecen obstáculos para ejercer su autonomía (CDHNU 2017, 4; 2003, 18) lo que mantiene la enorme brecha entre el reconocimiento de sus derechos en las legislaciones y la garantía efectiva de los mismos.

\section{AUTONOMÍA, LIBRE DETERMINACIÓN Y SISTEMAS JURÍDICOS INDÍGENAS EN MÉXICO}

Para hablar sobre sistemas jurídicos indígenas, primero es necesario comprender los derechos a la libre determinación y a la autonomía, pues ambos configuran el punto de partida para su desarrollo en Estados democráticos y pluriculturales, tal como México lo contempla en el artículo 2 o. constitucional.

Por un lado, el derecho a la libre determinación de los pueblos indígenas es el estatus jurídico que les da la libertad de establecer su propia organización política, económica, social y cultural, con el fin de que puedan dirigir su vida conforme a su cosmovisión, identidad, necesidades y prioridades (véase Organización de Estados Americanos 2016, artículo 3o., en adelante OEA; Naciones Unidas 2010, artículo 3o., en adelante ONU; ONU 2018, párrafo 35; Aragón y Color 2013, 500; Unión Africana 1981: artículo 20, inciso 1, en adelante UA). ${ }^{5}$

Asimismo, este derecho es indispensable para la preservación de su cultura $^{6}$ e identidad cultural. ${ }^{7}$ Pues sólo por medio del funcionamiento de

5 Declaración de las Naciones Unidas sobre los Derechos de los Pueblos Indígenas, artículo 3; cfr. Aragón, Orlando, y Color, Marycarmen, op. cit., p. 500; Unión Africana (UA), Carta Africana sobre Derechos Humanos y de los Pueblos, 1981, artículo 20, inciso 1; Declaración Americana de los Derechos de los Pueblos Indígenas, artículo 3o; ONU, Consejo de Derechos Humanos, Informe de la Relatora Especial del Consejo de Derechos Humanos sobre los derechos de los pueblos indígenas, A/73/176, 17 de julio de 2018, párr. 35 .

6 "La cultura de los pueblos indígenas se refiere a su forma particular de ser, ver y de actuar en el mundo, que surge por su estrecha relación con sus tierras, tradiciones y recursos naturales, constituyendo de esta forma su cosmovisión, religiosidad y su identidad cultural" (Corte Interamericana de Derechos Humanos 2010, párrafo 174, en adelante Corte IDH).

7 La identidad cultural es la identificación individual de los pueblos indígenas con el conjunto de tradiciones, valores, cosmovisiones y rituales, entre otros ( $c f r$. Tribunal Constitucional Plurinacional de Bolivia 2016, 14, en adelante TCPB). 
sus instituciones sociales y políticas, sin injerencias de terceros, es posible que continúen desarrollando su derecho consuetudinario, valores, usos y costumbres (Tribunal Electoral del Poder Judicial de la Federación 2011, 122-124, en adelante TEPJF).

Aunado a lo anterior, la autonomía también resulta un derecho matriz de los pueblos indígenas. Conforme a los estándares internacionales, ésta no involucra la separación del Estado para crear uno nuevo, sino, más bien, significa el derecho a un autogobierno para decidir sobre sus asuntos internos y crear sus propias normas (OEA 2016, artículo 21, inciso 1; CDHNU 2018, párrafo 3). ${ }^{8}$ A diferencia de la heteronomía, en donde las personas obedecen normas o valores morales creadas por una voluntad ajena (García Máynez 2013, 22).

Es a partir de esta base sólida, conformada por el derecho a la libre determinación y autonomía de los pueblos indígenas, que nace el derecho a mantener sus sistemas jurídicos conforme a sus propias instituciones, tradiciones, procedimientos, prácticas, y autoridades (OEA 2016, artículo 22). ${ }^{9}$

Ahora bien, de forma general, la doctrina ha definido que "el derecho no es un mero conglomerado de normas, sino que ellas se encuentran organizadas en sistemas más o menos complejos, esto es, conjuntos dotados de una cierta estructura u orden interno" (Rodríguez 2015, 981). Asimismo, la diversidad de sistemas jurídicos que existen en cada Estado son un reflejo de sus costumbres, convicciones, tradiciones e incluso creencias religiosas (Sirvent 2006, 5).

En los sistemas jurídicos indígenas sucede algo parecido, pues tienen sus propias estructuras organizativas, instituciones, normas, procedimientos, reparaciones, sanciones y autoridades. De igual forma, existe una gran diversidad de sistemas jurídicos indígenas que son un reflejo de sus culturas y costumbres diferentes, por lo que resulta muy dificil encontrar uno que sea exactamente igual a otro (CDHNU 2013, 49).

Sin embargo, existen algunas características que los aparatos normativos indígenas comparten. Una de ellas se deriva de la naturaleza colectiva

8 Cfr. Declaración de las Naciones Unidas sobre los Derechos de los Pueblos Indígenas.

9 Cfr. Declaración de las Naciones Unidas sobre los Derechos de los Pueblos Indígenas, artículo 5o y artículo 34; Convenio 169 sobre Pueblos Indígenas y Tribales en países independientes, artículo 8o., inciso 2. 
que comparten la mayoría de los pueblos indígenas, pues es sabido que los actos ilícitos que llegan a ocurrir dentro de su territorio afectan a toda la comunidad y a su tejido social. Por ello, es común que todos los integrantes participen en la resolución de los conflictos que se presenten, al ser sus valores los que se encuentran en juego (Bazurco y Exeni 2012, 129 y 131).

Otro aspecto característico es que usualmente los sistemas jurídicos indígenas buscan llegar con sus resoluciones a una justicia restaurativa. Lo que implica la participación de las partes del conflicto, sus familias y los miembros de la comunidad, para en conjunto determinar la reparación de los daños causados, la reinserción social de la persona, la armonía, el perdón y el equilibrio de toda la comunidad (cfr. CDHNU 2013, párrafo 52). Asimismo, es común que las fuentes de derecho de los sistemas jurídicos indígenas se presenten en leyes y practicas consuetudinarias orales, recurriendo a formas tradicionales de resolución de conflictos e incluso algunas veces a procesos contenciosos (Bazurco y Exeni 2012, 129).

Es necesario entender que los sistemas jurídicos indígenas siempre han formado parte de la vida e identidad de las personas indígenas, por lo que no son una invención contemporánea en el mundo jurídico. Son sistemas vivos, dinámicos y legítimos, que resultan accesibles a las personas indígenas por su proximidad y sentido de pertenencia (véase CDHNU 2013, párrafo 50), pues han logrado la construcción de la paz y tranquilidad de sus comunidades (véase Colmenares 2006, 56-99). Por ello, deben ser respetados y vistos con el mismo valor que se le da al sistema jurídico estatal.

\section{EL ARTíCULO 2o. CONSTITUCIONAL: HACIA UN DIÁLOGO INTERGULTURAL}

Como fue mencionado en apartados anteriores, en la actualidad el artículo 2o. de la CPEUM reconoce la autonomía de los pueblos indígenas para aplicar sus propios sistemas jurídicos para la resolución de conflictos internos, introduciendo principios que ayudan a comprender y proteger los derechos humanos de los pueblos indígenas. Uno de ellos, es el principio del pluralismo jurídico.

El pluralismo jurídico llega a cambiar la concepción de un monismo legal, en el que un sistema jurídico exclusivo (véase Ordóñez Cifuentes 
2008, 579) tiene el monopolio de la aplicación del derecho. Por lo tanto, el reconocer los sistemas jurídicos indígenas en la Constitución política debería implicar su coexistencia con el sistema jurídico del Estado, en condiciones de igualdad, donde ninguno sea superior al otro. Por lo que, surge la obligación de las autoridades estatales de respetarlos (TEPJF 2011, 133 y 134; OACNUDH México 2008, 35; SCJN 2013, 9).

A pesar de ello, la reforma constitucional del 2001 causó descontento y fue rechazada por la mayoría de los pueblos indígenas, pues a cada derecho adicionado a la Constitución se establecieron númerosos candados y restricciones que sólo dificultaban su verdadero ejercicio (CDHNU 2017, 14). Lo cual incluye su derecho de mantener y desarrollar sus propios sistemas jurídicos.

Por ejemplo, una de estas restricciones señala que los sistemas jurídicos indígenas no pueden ir en contra de derechos humanos. Para abordar este punto, es necesario entender desde una perspectiva jurídica y social, que en el mundo existen otros contextos culturales como el de los pueblos indígenas, así como otros sistemas de valores que - si bien pueden parecer diferentes a los que estamos acostumbrados desde una perspectiva occidental - son igual de válidos y legítimos (de Sousa 2014, 38).

Por ello, si en algún caso se alegara que la resolución o procedimiento de un sistema jurídico indígena violó derechos humanos de alguna de las partes, las autoridades estatales no pueden prejuzgar las prácticas tradicionales del pueblo indígena con argumentos basados en estereotipos o estigmas, y declarar per se, que en efecto existió una violación (TEPJF $2011,186)$.

En segundo lugar, cuando el artículo 2o. señala a la letra que "la ley establecerá los casos y procedimientos de validación por los jueces o tribunales correspondientes" genera complicaciones, pues delega a las autoridades estatales, constituciones y leyes reglamentarias la tarea de otorgarles validez, cuando ésta ya tendría que haber sido dada por el propio reconocimiento constitucional (véase CPEUM, artículo XII, inciso a, fracción II; OACNUDH México 2008, 46; CDHNU 2017, 10).

Asimismo, la SCJN ha señalado que el artículo 2o. constitucional establece una base mínima de derechos, la cual debe ser incluida y puede ser acrecentada por el orden jurídico de los estados (SCJN 2012, 49; CDHNU 2017, párrafo 15). En este sentido, se pensaría que, desde la reforma 
del 2001, las entidades federativas se han dedicado a realizar las adaptaciones correspondientes a sus legislaciones.

Sin embargo, aún hay algunas ${ }^{10}$ que en sus constituciones ni siquiera regulan expresamente lo concerniente a los sistemas jurídicos indígenas, o les dan a un papel meramente "alternativo" en contraposición con la jurisdicción ordinaria (Constitución de Yucatán, artículo II, párrafo 11), generando una especie de subordinación. Por ejemplo, en Chiapas se crearon autoridades independientes para resolver los conflictos que surgen en los pueblos indígenas, sobreponiéndose a sus autoridades originales y provocando el desconocimiento de sus sistemas jurídicos (OACNUDH México 2008, 77; Ley de Derechos y Culturas Indígenas del Estado de Chiapas, artículo XII). A su vez, la Constitución de Nayarit establece que la ley regulará la "eficacia" de los sistemas jurídicos indígenas (artículo VIII), cuestionando la legitimidad de estos.

Lo anterior sólo ha generado situaciones sumamente inestables, pues cada entidad federativa le da un distinto reconocimiento y reglamentación a este derecho, lo que provoca que en la mayoría de los casos no exista un verdadero pluralismo jurídico que sea integral y tangible, impidiendo a los pueblos indígenas mantener y desarrollar sus propios sistemas jurídicos, que forman parte de su identidad cultural.

Por otro lado, es posible tomar como referente de una buena práctica y apropiada adecuación del derecho a la Constitución Política de la Ciudad de México. En ella se reconocen los sistemas jurídicos indígenas para la resolución de sus conflictos internos, introduce una interpretación intercultural de los derechos humanos, ${ }^{11}$ y establece que habrá una coordinación entre las autoridades de los pueblos indígenas con los tribunales de la Ciudad de México en los casos en que sea necesario (Constitución Política de la Ciudad de México, artículo XIX, apartado B, inciso 8, fracción 3). Sería necesario revisar en un futuro próximo si dicha legislación realmente es efectiva en la práctica.

10 Constituciones de Michoacán de Ocampo, Aguascalientes, Baja California Sur, Coahuila de Zaragoza, Guanajuato, Nuevo León, Tamaulipas y Zacatecas.

11 La traducción intercultural se refiere a que los propios derechos fundamentales deben someterse a una interpretación intercultural. Es decir que, "los valores plasmados en esos derechos deben ser respetados, pero las actuaciones concretas que los respetan o que los violan no siendo éticamente neutras, pueden ser objeto de interpretaciones opuestas conforme a las normas culturales de las que se parta" (de Sousa Santos 2012, 41). 
Ahora bien, una herramienta fundamental para mantener la convivencia y coexistencia cuando surgen conflictos de competencia es la coordinación entre jurisdicciones, sin embargo, en la mayoría de las legislaciones estatales y federales no se toma en cuenta (OACNUDH México 2008, 52). La falta de un procedimiento claro de coordinación sólo contribuye a que aumenten las fricciones entre jurisdicciones, y provoca a su vez una subordinación de la jurisdicción indígena a la ordinaria.

De igual forma, otra herramienta indispensable para que un pluralismo jurídico se materialice efectivamente en la realidad y se logre mantener una verdadera interacción armoniosa entre sistemas jurídicos, es la apertura a un diálogo intercultural.

$\mathrm{Al}$ respecto, tal como señala la reconocida doctora Catherine Walsh, la interculturalidad crítica pretende dejar de invisibilizar que las desigualdades en la sociedad se originan y construyen a partir de un pasado marcado por el colonialismo, en donde la cultura dominante u occidental aún prevalece sobre la cultura de los pueblos indígenas (Walsh 2019, 4). ${ }^{12}$

Por ello, dicha interculturalidad surge como un proceso que ayuda a reconocer las diferencias y la diversidad que nos caracteriza a todos como seres humanos, con el fin de buscar nuevas formas de relacionarnos y de construir caminos para vivir en una sociedad realmente "justa, equitativa, igualitaria y plural" (Walsh 2009, 2).

De ahí que diversas doctrinas han señalado al diálogo intercultural como la solución a los conflictos que surgen en las sociedades pluriculturales, pues tiene la función de ser una herramienta que pueda garantizar la convivencia entre distintos sistemas jurídicos bajo un marco de igualdad y respeto, en el que reconozcan tanto sus aciertos como deficiencias para aprender una de la otra, complementarse y generar acuerdos mutuos (véase Walsh 2019, 15; OACNUDH México 2008, 33 y 34; Bazurco y Exeni 2012,34). A diferencia, por ejemplo, de un multiculturalismo liberal, en el cual la interacción entre culturas es más bien asimétrica y distante, la cultura dominante (normalmente la occidental) es la que predomina sin ni siquiera cuestionarse, y no existe realmente una comunicación o

12 Cfr. Walsh, Catherine, "Interculturalidad crítica y educación intercultural", 2019, Construyendo interculturalidad crítica, La Paz, Instituto Internacional de Integración del Convenio Andrés Bello, 4.

Esta obra está bajo una Licencia Creative Commons

Atribución-NoComercial-SinDerivar 4.0 Internacional, IIJ-UNAM.

Boletín Mexicano de Derecho Comparado, núm. 158, mayo-agosto de 2020, pp. 619-650. 
compresión entre culturas que permita escuchar y conocer la perspectiva del otro (Vásquez Gutiérrez 2013, 5).

1) Por lo tanto, para que puedan operar en la realidad los diálogos interculturales entre el sistema jurídico estatal y los diversos sistemas jurídicos indígenas en México, considero necesario: crear las condiciones necesarias para que exista una relación igualitaria y horizontal entre los dialogantes.

2) Asegurar que el diálogo se lleve a cabo en un contexto culturalmente adecuado, con el fin de que las partes expresen sus ideas conforme a su propia identidad.

3) Los dialogantes deberán tener siempre presente que existen otras visiones del mundo que son valiosas y necesarias para la diversidad cultural. Por ello, tendrán el deber de escuchar esas perspectivas, antes de asumir posturas totalitarias.

4) Los diálogos deberán tener como propósito enriquecer y transformar cada sistema jurídico (Sierra 2015, 312), sin que esto implique arriesgar o perder la identidad cultural que caracteriza a los dialogantes involucrados y al grupo que representan (Robles 2015, 268).

Es evidente lo complejo que puede llegar a ser mantener diálogos interculturales entre sistemas jurídicos diversos, pues además de los contextos completamente distintos a partir de los cuales se han construido, también existen relaciones asimétricas entre culturas arraigadas profundamente en la sociedad. Sin embargo y a pesar de dicha dificultad, considero que las circunstancias y desafios actuales exigen soluciones que puedan transformar gradualmente las relaciones entre seres humanos, hasta crear unas más justas, tolerantes y plurales. El diálogo intercultural debe tomarse en cuenta para lograrlo.

\section{EL DEBIDO PROCESO DEL SISTEMA JURÍDICO ESTATAL \\ Y CARACTERÍSTICAS DE LOS SISTEMAS JURÍDICOS INDÍGENAS EN MÉXICO}

En el presente apartado abordaré, en primer lugar, lo que se entiende como debido proceso del sistema jurídico estatal desde una concepción 
occidental. Posteriormente, realizaré una breve reseña de las características que conforman algunos sistemas jurídicos indígenas de México.

La importancia del debido proceso estatal radica en que es un medio para la garantía y tutela de todos los derechos humanos (véase Medina 2003, 267; García Ramírez 2012, 5), su conceptualización es compleja pues implica un conjunto de elementos que deben tener las instancias procesales de un sistema jurídico, con el propósito de asegurar que las partes del conflicto puedan en condiciones de igualdad procesal defender sus derechos y alcanzar la justicia (véase Fix 1987, 820-822; Corte IDH 2001, párrafo 69; Corte IDH 1987, párrafos 27 y 28).

De igual forma, una de sus características es que no es estático, pues es común que se vayan agregado nuevos elementos procesales a los ya existentes, por lo que siempre está constante evolución. ${ }^{13}$

Los elementos que integran el debido proceso se encuentran en diversas fuentes. Por un lado, la Constitución Política se refiere a éstos, en "forma de referencias, normas rectoras, instrucciones o fundamentos del enjuiciamiento penal" (García Ramírez 2012, 13), específicamente en los artículos 13, 14, 16, 17, 20, 21, entre otros.

Algunos de estos elementos son los siguientes: juez competente e imparcial; audiencia ante tribunales previamente establecidos; y emisión de resoluciones debidamente fundadas y motivadas por leyes previamente establecidas.

Por otro lado, en el Pacto Internacional de los Derechos Civiles y Políticos también se pueden encontrar algunos elementos en el artículo 14, a saber: derecho a ser oído por tribunales competentes, independientes e imparciales; igualdad de las partes; principio de presunción de inocencia, entre otros.

Asimismo, la Convención Americana sobre Derechos Humanos (en adelante CADH) contiene bajo el título de "garantías judiciales" del artículo 8o., párrafo 1, el derecho de toda persona "a ser oída, con las debidas garantías y dentro de un plazo razonable, por un juez o tribunal competente, independiente e imparcial, establecido con anterioridad por la ley". Estas garantías mínimas deben cumplirse en cualquier proceso sin

13 Voto concurrente razonado del juez Sergio García Ramírez a la $O C$-16/99 sobre El derecho a la información sobre la asistencia consular en el marco de las garantías del debido proceso legal, del 1o. de octubre de 1999, Serie A, núm. 16, párrafo 9. 
importar la materia de que se trate, ya sea: laboral, civil, administrativo, etcétera (Corte IDH 2001, párrafo 103).

Por otro lado, el párrafo 2 del artículo 8o. señala las garantías judiciales específicamente en materia penal, sin embargo, no se limitan únicamente a las enunciadas en dicha disposición, pues la Corte IDH se ha dedicado a realizar, a lo largo de los años, una interpretación extensiva de estas (García Ramírez 2012, 17).

Ahora bien, después de comprender lo que es el debido proceso del sistema jurídico estatal, en el cuadro siguiente describiré brevemente la composición de algunos sistemas jurídicos indígenas. Para ello, me limitaré a mencionar la información recopilada de documentos de investigación realizados por la SCJN y la OACNUDH México, los cuales enfocaron su estudio exclusivamente en los pueblos indígenas a los que haré referencia.

Asimismo, es necesario aclarar que la siguiente descripción no pretende agotar todas las particularidades que conforman a cada uno de los sistemas jurídicos indígenas. Pues tal como recalqué en párrafos anteriores, al ser éstos sumamente diversos y dinámicos, no sería posible asumir una postura determinista al respecto.

\begin{tabular}{|l|l|}
\hline \multicolumn{2}{|c|}{ fueces, asambleas, consejo tradicional, comisarios, entre otros } \\
\hline & $\begin{array}{l}\text { Los jueces de paz }{ }^{14} \text { se encargan de administrar justicia } \\
\text { en los municipios de composición indígena (OACNUDH } \\
\text { México 2008, 57). } \\
\text { En la actualidad los jueces de paz son propuestos por } \\
\text { los presidentes municipales ante el Tribunal Superior de } \\
\text { Justicia, órgano encargado de nombrarlos; anteriormente } \\
\text { eran elegidos por la población de cada municipio de forma } \\
\text { maya } \\
\text { Ubicación: Yucatána } \\
\text { tradicional (OACNUDH México 2008, 62), por lo que } \\
\text { sentían más cercano el sistema de justicia (OACNUDH } \\
\text { México 2008, 52 y 62). }\end{array}$ \\
\hline
\end{tabular}

14 Constitución del Estado de Yucatán, artículo 75, fracción lll; Ley Orgánica del Poder Judicial del Estado de Yucatán, artículo 56 y 57.

Esta obra está bajo una Licencia Creative Commons Atribución-NoComercial-SinDerivar 4.0 Internacional, IIJ-UNAM. Boletín Mexicano de Derecho Comparado, núm. 158, mayo-agosto de 2020, pp. 619-650. 


\begin{tabular}{|c|c|}
\hline $\begin{array}{l}\text { Pueblo indígena } \\
\text { maya } \\
\text { Ubicación: Chiapas }\end{array}$ & $\begin{array}{l}\text { Los Jjmeltsa'anwanejetic (jueces tzeltales), duran en su } \\
\text { cargo } 3 \text { años y son mediadores en la resolución de conflictos, } \\
\text { aplicando las prácticas jurídicas tzeltales tradicionales } \\
\text { (OACNUDH México 2008, 84). } \\
\text { La normativa tradicional tzeltal establece que este cargo } \\
\text { debe ser asumido en conjunto por un hombre y una mujer; } \\
\text { el objetivo es atender adecuadamente los casos en que las } \\
\text { mujeres son víctimas de violencia, siendo fundamental su } \\
\text { participación (OACNUDH México 2008, } 84 \text { y 85). } \\
\text { Los jueces tzeltales resuelven los conflictos de forma } \\
\text { colectiva, por medio de un Colegio de jueces (OACNUDH } \\
\text { México 2008, 84). } \\
\text { El nombramiento de los jueces tzeltales se da en asamblea } \\
\text { y en presencia de quienes los han elegido (OACNUDH } \\
\text { México 2008, 86). } \\
\text { En este sistema de justicia, la imparcialidad del juez } \\
\text { tzeltal es fundamental para llegar a una conciliación entre } \\
\text { las partes. } \\
\text { "El juez debe ser una persona de alta calidad moral, } \\
\text { equilibrada y de buen corazón, de buen pensar, que } \\
\text { contribuye a la resolución de un asunto, que no daña el } \\
\text { corazón ni el pensar de nadie, que más bien, ayuda a } \\
\text { mantener la paz colectiva comunitaria" (López Sánchez } \\
\text { 2018, 206). } \\
\text { La impartición de justicia es gratuita, pues tiene como } \\
\text { función ayudar a la comunidad (OACNUDH México } \\
\text { 2008, 89). }\end{array}$ \\
\hline
\end{tabular}

15 Este sistema jurídico busca la conciliación entre las partes, y la reparación del daño de la víctima en el conflicto. Al llegar a la conciliación esperada se levanta un acta en la que consiste la resolución del caso (entrevista con hombres jueces tzeltales, Chiapas) (OACNUDH México 2008, 87). 


\begin{tabular}{|c|c|}
\hline $\begin{array}{l}\text { Pueblos indígenas } \\
\text { tlapanecos, mixtecos } \\
\text { y náhuas }{ }^{16} \\
\text { Ubicación: Guerrero }\end{array}$ & $\begin{array}{l}\text { Las autoridades inmediatas a las que acuden se llaman } \\
\text { comisarios (OACNUDH México 2008, } 92 \text { y 93), para } \\
\text { resolver conflictos que surjan dentro de sus comunidades, } \\
\text { siempre que éstos no sean de gravedad. } \\
\text { Los conflictos graves se resuelven en otra instancia } \\
\text { integrada por distintos representantes que analizan en } \\
\text { conjunto esos casos. }\end{array}$ \\
\hline $\begin{array}{l}\text { Pueblo indígena } \\
\text { mixteco } \\
\text { Ubicación: Oaxaca, } \\
\text { Guerrero y Puebla }^{17}\end{array}$ & $\begin{array}{l}\text { Una asamblea es la autoridad máxima (López Sarabia } \\
\text { 2018, 170). Las personas que se encargan de resolver los } \\
\text { conflictos se les llaman te'e axi ña'a nee tiñu, jiene kuatyi, } \\
\text { que significa: "hombre o mujer que tiene el cargo de cortar } \\
\text { el problema" (OACNUDH México 2008, 170). } \\
\text { A las autoridades locales de cada núcleo rural les toca } \\
\text { resolver el Kuatyi (el problema) en primera instancia; } \\
\text { el síndico y alcalde del municipio resuelven en segunda } \\
\text { instancia (OACNUDH México 2008, 170). }\end{array}$ \\
\hline $\begin{array}{l}\text { Pueblo indígena } \\
\text { O'dam } \\
\text { Ubicación: Durango }\end{array}$ & $\begin{array}{l}\text { La figura es conocida como juez o jefe de cuartel. } \\
\text { No tienen autoridad para decidir sobre los casos, lo que } \\
\text { hacen es convocar a una asamblea comunitaria para llegar } \\
\text { a una resolución de forma comunal, el juez o jefe de cuartel } \\
\text { sólo se encarga de ejecutarla (Mendía 2018, } 188 \text { y 189). }\end{array}$ \\
\hline $\begin{array}{l}\text { Pueblo indígena } \\
\text { Wizarika } \\
\text { Ubicación: Nayarit }\end{array}$ & $\begin{array}{l}\text { La figura se encuentra en forma de un consejo tradicional } \\
\text { de ancianos (Muñoz 2018, 216). }\end{array}$ \\
\hline
\end{tabular}

16 La coordinadora regional de autoridades comunitarias de la Costa Chica y Montaña de Guerrero (CRAC), es una organización regional mayoritariamente indígena, cuyo objetivo principal es garantizar la seguridad pública de sus pueblos e impartir justicia. Esta organización abarca a 65 comunidades distribuidas en 10 municipios distintos, que incluyen a tres pueblos indígenas: tlapanecos, mixtecos y náhuas. Entre sus funciones se encuentra la de administrar justicia (OACNUDH México 2008, 93).

17 Debido al fenómeno de la migración, también pueden encontrarse en la Ciudad de México, San Luis Potosí, Jalisco, Baja California y Baja California Sur (OACNUDH México 2008, 169).

18 Las resoluciones dependen de las circunstancias en las que se generó el Kuatyi, del arrepentimiento de quien lo cometió, y el compromiso de no repetición frente a las autoridades y familiares. Asimismo, las medidas pueden ser desde sanciones económicas, hasta morales (OACNUDH México 2008, 171). 
Audiencias orales, representación y partes del proceso

\begin{tabular}{|c|c|}
\hline $\begin{array}{l}\text { Pueblo indígena } \\
\text { maya } \\
\text { Ubicación: Yucatán }\end{array}$ & $\begin{array}{l}\text { Se llevan a cabo audiencias orales para la resolución de } \\
\text { conflictos, en donde se encuentran presentes el acusador, el } \\
\text { acusado y las o los juzgadores (Shwant 2005, 263). }\end{array}$ \\
\hline $\begin{array}{l}\text { Pueblo indígena } \\
\text { maya } \\
\text { Ubicación: Chiapas }\end{array}$ & $\begin{array}{l}\text { Después de que alguna de las partes acude con los jueces } \\
\text { tzeltales a pedir su intervención en el conflicto, los jue- } \\
\text { ces tienen la facultad de convocar a una audiencia para llegar } \\
\text { a un acuerdo conciliatorio (OACNUDH México 2008, 87). }\end{array}$ \\
\hline $\begin{array}{l}\text { Pueblos indígenas } \\
\text { tlapanecos, mixtecos } \\
\text { y náhuas } \\
\text { Ubicación: Guerrero }\end{array}$ & $\begin{array}{l}\text { Las familias representan al acusado, ellas asumen el } \\
\text { compromiso de hacer cumplir las resoluciones a las que se } \\
\text { lleguen y a su vez la reparación correspondiente. }{ }^{19}\end{array}$ \\
\hline $\begin{array}{l}\text { Pueblo indígena } \\
\text { mixteco } \\
\text { Ubicación: Oaxaca, } \\
\text { Guerrero y Puebla. }\end{array}$ & $\begin{array}{l}\text { Las audiencias se llevan a cabo de forma oral, con la } \\
\text { presencia de las partes involucradas en el conflicto, los } \\
\text { familiares, parientes, padrinos y personas que colaboren a } \\
\text { resolver el kuatyi (el problema) (López Sarabia 2018, } 170 \\
\text { y 171). }\end{array}$ \\
\hline $\begin{array}{l}\text { Pueblo indígena } \\
\text { O'dam } \\
\text { Ubicación: Durango }\end{array}$ & $\begin{array}{l}\text { Para llegar a una resolución, participan la estructura de } \\
\text { gobierno (civil, religiosa y agraria), la persona que cometió } \\
\text { el hecho ilícito, sus familiares, y los comuneros. } \\
\text { No existen especialistas que se encarguen como tal de } \\
\text { llevar la figura de una defensa, más bien, entre los actores } \\
\text { mencionados con anterioridad se reconstruyen los hechos y } \\
\text { se van proponiendo resoluciones (Mendía 2018, 189). }\end{array}$ \\
\hline
\end{tabular}

19 Los conflictos se resuelven por medio de un acuerdo mutuo de conciliación que es reconocido por la asamblea por medio de un acta firmada. Si la parte que cometió el hecho ilícito no cumple con el acuerdo, se le somete a un mecanismo conocido como reeducación, que consiste en realizar trabajo comunitario rotándose cada 15 días en diversas comunidades, en donde se le proporciona comida, un lugar para vivir, y el trabajo que deberá realizar. El periodo de reeducación dura el tiempo que la persona indígena hubiera permanecido privada de su libertad en un sistema de justicia ordinario (OACNUDH México 2008, 94). 


\begin{tabular}{|c|c|}
\hline $\begin{array}{l}\text { Pueblo indígena } \\
\text { Wizarika } \\
\text { Ubicación: Nayarit }\end{array}$ & $\begin{array}{l}\text { Las personas que conocen a fondo sus sistemas, costumbres } \\
\text { y tradiciones son las que se encargan de desempeñar este } \\
\text { papel (Muñoz 2018, 216). }\end{array}$ \\
\hline \multicolumn{2}{|r|}{ Principios, normas orales y sistemas de valores } \\
\hline $\begin{array}{l}\text { Pueblo indígena } \\
\text { mixteco } \\
\text { Ubicación: Oaxaca, } \\
\text { Guerrero y Puebla. }\end{array}$ & $\begin{array}{l}\text { No hay una clasificación de delitos o de materias. Ellos se } \\
\text { refieren a estos como Kuatyi (el problema) (López Sarabia } \\
2018,170 \text { ). } \\
\text { Tienen principios que para ellos es fundamental respetar, } \\
\text { que se manifiestan de la siguiente forma: "iyo tu'un nakeeno } \\
\text { nu seya ñuu, so suni iyo skunkuvin nu ñuo, ne saá je katyi } \\
\text { seya ñuu, ya ñ+v+ naa kuvin nu ntakao", que significa: } \\
\text { "tienes derechos que te protegen como ciudadano, pero } \\
\text { también debes cumplir con tus obligaciones, hasta en ese } \\
\text { momento serás una persona de bien" (López Sarabia 2018, } \\
\text { 170). }\end{array}$ \\
\hline $\begin{array}{l}\text { Pueblo indígena } \\
\text { O’dam } \\
\text { Ubicación: Durango }\end{array}$ & $\begin{array}{l}\text { Tienen principios y normas que se reproducen y sociabilizan } \\
\text { en su organización familiar, llamada Kikcham, y asimismo } \\
\text { en su organización de pueblo, llamada Pue'mblo. Estos } \\
\text { espacios también funcionan para regularlas y sancionarlas } \\
\text { (Mendía Soto } 2018,179 \text { y 181). } \\
\quad \text { No hay códigos escritos, pues sus principios y normas se } \\
\text { transmiten mediante la oralidad y la práctica. Sus procesos } \\
\text { también son orales (Mendía Soto } 2018,187 \text { y 188). }\end{array}$ \\
\hline $\begin{array}{l}\text { Pueblo indígena } \\
\text { Wizarika } \\
\text { Ubicación: Nayarit }\end{array}$ & $\begin{array}{l}\text { Sus principios y normas nacen y se transmiten de forma } \\
\text { oral, por medio de tradiciones y a través de asambleas con } \\
\text { la participación de todas las personas de la comunidad } \\
\text { (Muñoz 2018, 216). } \\
\text { Tras los enjuiciamientos, las asambleas o consejos van } \\
\text { catalogando las conductas y las correspondientes sanciones } \\
\text { (Muñoz 2018, 217). }\end{array}$ \\
\hline
\end{tabular}

Enunciado lo anterior, resulta evidente que los sistemas jurídicos indígenas mencionados tienen procesos para resolver sus conflictos internos que dependen en su totalidad de su propia cosmovisión, tradiciones e identidad cultural. No debe olvidarse que la situación es la misma cuando 
nos referimos al sistema jurídico estatal, pues cada uno tiene una construcción histórica y cultural propia.

Por esa razón, en los siguientes párrafos analizaré las características de los sistemas jurídicos indígenas que fueron descritas, con el propósito de comprender por qué es necesario respetarles tal y como son concebidos.

En primer lugar, si abordamos este punto desde una perspectiva occidental, es posible afirmar que los sistemas jurídicos indígenas tienen lo que nosotros conocemos como "juez u órgano competente, independiente e imparcial". Sin embargo, en sus procesos esta figura se presenta en forma de jueces individuales, o bien, en forma de asambleas, consejos tradicionales, comisarios, entre otros. Asimismo, a menudo asumen un papel conciliador o se encargan de ejecutar las resoluciones, ya que éstas se determinan en la mayoría de los casos de forma colectiva.

Por ello, si bien es claro que los sistemas jurídicos indígenas no tienen una figura de juez idéntica a la de una sociedad occidental, éste no debería ser un argumento para impedirles desarrollar sus sistemas jurídicos. Pues las autoridades u órganos que se encargan de resolver sus conflictos cuentan con:

1) Competencia: los propios pueblos indígenas al cual pertenecen los sistemas jurídicos les dotan de la misma, además del artículo 20. constitucional, las constituciones estatales y los tratados internacionales en la materia.

2) Imparcialidad e independencia: estos requisitos resultan de vital importancia para los sistemas jurídicos indígenas, pues se podría afirmar que con estas características sus jueces u órganos cumplen con su propósito, que no sólo consiste en que la víctima obtenga una reparación, o que la persona que infringió sus normas y principios se reinserte en la comunidad, sino también conforme a su identidad cultural colectiva: el restablecer la armonía, unión y el tejido social de su comunidad.

Como segundo punto, la figura de una defensa en el proceso se encuentra en la mayoría de los sistemas jurídicos mencionados, en los familiares de las partes involucradas en la controversia o las personas que son parte de la comunidad y que conocen a fondo sus tradiciones. Estas personas son comúnmente las encargadas de asumir un papel de representa- 
ción para apoyar a llegar a una conciliación y restablecer el equilibrio de la comunidad. En tercer lugar, sus procesos se llevan a cabo de forma oral en audiencias públicas, con la presencia de las partes, de la comunidad y de sus representantes. Como último punto, sus normas, principios y sistemas de valores acostumbran en la mayoría de los casos, a ser orales y a transmitirse por medio de sus tradiciones.

Ahora, para analizar por qué estos tres últimos elementos que conforman los sistemas jurídicos indígenas requieren ser respetados sin importar las diferencias que tengan con el debido proceso occidental, tomaré como referencia las aportaciones hechas por tribunales constitucionales de Estados latinoamericanos que reconocen al igual que México, el ser países pluriculturales.

En primer lugar, la Corte Constitucional de Colombia ha establecido que, desde una postura de respeto a la cultura de cada pueblo indígena, no es posible exigirles que los elementos procesales que conforman sus sistemas jurídicos sean exactos a los que conocemos (véase Corte Constitucional Colombiana 1996, en adelante CGC). Por ello, no existe una vulneración al debido proceso si las jurisdicciones indígenas resuelven los casos concretos actuando conforme a sus propios usos, costumbres y prácticas tradicionales que han sido el sustento de su cohesión social (CCG 1996; 1997).

Asimismo, el TCPB se ha pronunciado en la misma lógica, a partir de los sólidos principios de un Estado plurinacional e intercultural, al señalar que las jurisdicciones indígenas no pueden tener los mismos elementos del debido proceso de una jurisdicción ordinaria, pues éstos obedecen legítimamente a tradiciones jurídicas diferentes (TCPB 2016, 9). Por ello, en casos de controversias, el tribunal constitucional sólo debería cerciorarse, por un lado, de que la persona haya podido asumir una defensa, y por otro, de que la resolución no afecte sus derechos a la vida, a la dignidad y a la integridad física (TCPB 2016, 9).

Por último, el Tribunal Constitucional de Ecuador señaló en una de sus sentencias respecto al pueblo indígena Kichwa Panzaleo, que a pesar de no encontrarse de forma escrita los procedimientos para resolver sus conflictos, sí contaban con normas orales establecidas previamente que eran claras, públicas y respetadas por toda la comunidad (Tribunal Constitucional del Ecuador 2014, 20). 
Por lo tanto, considerando lo desarrollado por los mencionados tribunales que dan luz sobre el tema, y asimismo que, "desde una perspectiva intercultural se debe tomar en cuenta que cada sistema de justicia tiene maneras distintas y propias de garantizar el valor constitucional del debido proceso" (de Sousssa 2012, 43), es posible llegar a las siguientes conclusiones:

Los elementos que conforman los sistemas jurídicos indígenas se presentarán de forma distinta a la que estamos acostumbrados en una jurisdicción estatal, no es posible pretender que se limiten sus características esenciales o intentar que sean iguales a los elementos que conforman el debido proceso desde una perspectiva occidental y dominante. Hacerlo implicaría intentar asimilarlos y privarles de sus derechos a la libre determinación y autonomía.

Esto no significa que los procesos de los sistemas jurídicos indígenas sean incompletos o carentes de garantías - pues esta visión sería contraria a la de un verdadero Estado pluricultural - simplemente implica que deben reconocerse sus diferencias como pertenecientes a su propia historia, cultura y contextos. Asimismo, se debe respetar que, desde su propia perspectiva y forma de ver el mundo, sus procedimientos son legítimos, así como un camino idóneo para resolver sus conflictos internos, buscar y obtener justicia.

\section{SISTEMAS JURÍDICOS INDÍGENAS EN MATERIA PENAL: CRÍTICA al Código Nacional de Procedimientos Penales}

A pesar de su reciente creación y vigencia en nuestro orden legislativo, el Código Nacional de Procedimientos Penales (en adelante CNPP) cumple con una tarea importante: el ser un código procesal único para toda la república que asegura un nuevo sistema de justicia penal (Gómez 2015, 13). Se publicó en el Diario Oficial de la Federación el 5 de marzo de 2014, y sus disposiciones son de "observancia general en toda la República Mexicana" (CNPP, artículo 1o.).

Es aquí en donde el derecho de los pueblos indígenas de mantener y desarrollar sus propios sistemas jurídicos - específicamente en materia penal - no pasa desapercibido, pues incorpora un apartado especial denominado "Procedimientos especiales" dentro del capítulo I, artículo 420, donde establece algunas cuestiones que a continuación se analizarán. 
En sus primeras líneas, el artículo establece que las jurisdicciones indígenas pueden resolver respecto a delitos que afecten bienes jurídicos de éstos o de alguno de sus miembros, siempre y cuando las partes en el conflicto de forma voluntaria den su consentimiento para someterse a dichos sistemas. Este último requisito, el de otorgar un consentimiento, visibiliza una restricción desproporcional que se les imponen a los sistemas jurídicos indígenas y que cuestionan su legitimidad. Pues ni siquiera la jurisdicción estatal penal requiere obtener alguna clase de consentimiento de las partes en un proceso de su competencia.

A su vez, el artículo señala algunos derechos que deben respetar las resoluciones emitidas por las jurisdicciones indígenas, los que consisten en: a) considerar una perspectiva de género; $b$ ) no afectar la dignidad y el interés superior de los niños y niñas; c) respetar el derecho a una vida libre de violencia hacia la mujer.

Para analizar este último apartado del CNPP, tomaré como referencia los pronunciamientos de la CGC, cuando señala que no todas las normas constitucionales pueden ser un límite para los sistemas jurídicos de los pueblos indígenas, ya que, de ser así, no habría realmente un pluralismo jurídico que respetara su diversidad cultural (CCG 1996; Solano 2004, 7).

Por lo tanto, la CCG decide crear un listado de derechos humanos específicos que los pueblos indígenas deben respetar al resolver conflictos por medio de sus propios sistemas jurídicos, el cual es conformado por el derecho a la vida, la prohibición de la esclavitud, y prohibición de la tortura.

Siguiendo esta lógica, podría interpretarse que los derechos enunciados por los legisladores de forma expresa en el CNPP pretendían tener una función parecida, al establecer por medio de un marco legal qué derechos humanos deben respetar en sus resoluciones los sistemas jurídicos indígenas en asuntos de la materia penal.

En ese sentido, si existiera alguna resolución de una jurisdicción indígena que presuntamente no respeto derechos humanos, primero se tendría que asumir una postura respetuosa a su identidad cultural y a partir de ahí, realizar estudios acordes con los principios de un Estado pluricultural, con el fin de construir una traducción intercultural de los derechos humanos. Ese es el deber que habría de adoptar el Estado mexicano para respetar el derecho de los pueblos indígenas a mantener sus sistemas jurídicos. 
A pesar de lo anterior, el artículo 420 sólo establece que para atender este tipo de casos "cualquier miembro de la comunidad indígena podrá solicitar que así se declare ante el juez competente", omitiendo por completo el esclarecer algunos puntos importantes.

Por ejemplo, no establece si dicha solicitud sólo puede provenir de una persona indígena o si también la puede hacer alguien que no es parte de la comunidad (García Ramírez 2018, 649); no señala de forma clara cuál es el procedimiento que deberá seguirse en dichas situaciones; no determina quién es el supuesto "juez competente" ante el cual acudir, y tampoco señala si existirá algún tipo de coordinación o diálogo intercultural con el pueblo indígena involucrado.

Por otro lado, el artículo 420 del CNPP señala en sus últimas líneas que las jurisdicciones indígenas no tienen competencia para resolver delitos que prevén prisión preventiva oficiosa. Por lo tanto, al ser ésta una limitación material a su competencia, si una persona indígena llegara a realizar un acto ilícito dentro de estos supuestos, deberá someterse a un sistema jurídico estatal.

Para abordar este último punto, me limitaré a señalar algunas de las dificultades que enfrentan las personas indígenas cuando son obligadas a someterse a dichas jurisdicciones.

En México persiste un alarmante contexto en el cual las personas indígenas imputadas en procesos penales sufren de inconsistencias y violaciones a su debido proceso, pues no reciben información sobre sus derechos humanos de forma inmediata y culturalmente adecuada, existe una insuficiencia de intérpretes o traductores que les apoyen durante el proceso y pocos defensores que hablen su lengua para ejercer una defensa técnica (CNDH 2018; Comisión Interamericana de Derechos Humanos 2015, párrafo 256).

En ese sentido, los datos demuestran que el Instituto Federal de Defensoría Pública tiene la posibilidad de cubrir una defensa penal en 34 lenguas indígenas, sin embargo, esta cantidad no es suficiente, pues en el Estado mexicano existen aproximadamente 68 lenguas con sus diversas variantes; es decir, "por cada 600,000 habitantes indígenas hay sólo un defensor público federal” (Saúl y Rosario 2017).

Asimismo, la Comisión de Justicia de la Cámara de Diputados ha señalado que deben tomarse acciones urgentes para garantizar el derecho de las personas indígenas a un debido proceso desde su detención y a lo 
largo de éste, siendo la falta de intérpretes una de las inconsistencias más graves (Fondo para el Desarrollo de los Pueblos Indígenas de América Latina y el Caribe, Más de 8 mil indígenas en la cárcel por falta de traductores en México 2019).

Es el caso, por ejemplo, de Teresa González, Iberta Alcántara y Jacinta Francisco, tres indígenas hñähñu, quienes fueron acusadas por haber secuestrado a 6 agentes federales, delito que en realidad nunca cometieron. Su detención fue hecha sin apego a la ley y en el proceso penal al que fueran sometidas no se les proporcionó traductores, intérpretes y tampoco fueron admitidas las pruebas que comprobaban su inocencia (véase Centro Prodh). ${ }^{20}$

Lo anterior tuvo como consecuencia que fueran sentenciadas a una pena de prisión por 21 años, permaneciendo en un centro penitenciario por 1335 días, hasta que recibieron apoyo legal del Centro de Derechos Humanos Miguel Agustín Pro Juárez (Centro Prodh) y finalmente fueron liberadas, recibiendo a su vez una disculpa pública por la Procuraduría General de la República (Castillo 2017; García Jacobo 2017).

Esta situación ha generado que organismos internacionales se pronuncien al respecto, al señalar que los índices de personas indígenas que se encuentran en centros penitenciarios son desproporcionadamente altos debido a la discriminación que padecen en los procedimientos judiciales penales de las jurisdicciones estatales (CDHNU 2013, 43).

Por lo tanto, es evidente que además de obligar a las personas indígenas a someterse a un sistema jurídico estatal totalmente ajeno a su identidad cultural, valores y tradiciones, también sus derechos humanos son transgredidos en dichos procesos penales, dejándolos sin seguridad jurídica.

Lo anterior demuestra la necesidad de generar una verdadera transformación institucional del sistema jurídico del Estado para que sea realmente pluricultural. Asimismo, cuestiona su efectividad para garantizar los derechos de las personas indígenas y reafirma la libertad que se les debe dar para resolver sus conflictos internos por medio de sus propios sistemas jurídicos, los cuales son cercanos a ellos y claramente, culturalmente apropiados.

20 Cfr. Centro Prodh, Alberta Alcántara y Teresa González. Disponible en http://centroprodh.org. $m x /$ casos-3/alberta-alcantara-y-teresa-gonzalez/ 


\section{CONCLUSIONES}

Después de haber analizado el derecho de los pueblos indígenas a mantener y desarrollar sus propios sistemas jurídicos y diversas características que constituyen algunos de ellos, mencionaré algunas conclusiones:

En primer lugar, el derecho a su libre determinación y autonomía son la base fundamental sobre la cual surge el derecho de los pueblos indígenas a mantener y desarrollar sus propios sistemas jurídicos.

Es así como en el artículo 2o. de la CPEUM se reconoce que el Estado mexicano tiene una "composición pluricultural sustentada originalmente es sus pueblos indígenas", e introduce a su vez el principio de pluralismo jurídico, el cual debería permitir la coexistencia entre diversos sistemas jurídicos en un mismo Estado. Sin embargo, al analizar dicho artículo, se encontraron algunas cuestiones que resultaría adecuado solucionar:

1) La CPEUM establece que la validez de los sistemas jurídicos indígenas será hecha por otras autoridades y tribunales competentes, cuando ésta tendría que ser dada por el propio reconocimiento constitucional.

2) Las constituciones de cada entidad federativa de la república varían en cuanto al reconocimiento que les dan a los sistemas jurídicos indígenas, provocando una falta de certeza jurídica a su derecho de mantenerlos y desarrollarlos conforme a su identidad cultural.

3) Antes de determinar en algún caso si los sistemas jurídicos indígenas respetaron los límites que establece la Constitución, siendo éstos los derechos humanos, debe hacerse una traducción intercultural que tome en cuenta su cosmovisión particular e identidad. Para ello, una sugerencia es que debería existir de forma expresa en el texto constitucional o en alguna ley secundaria un procedimiento a seguir que sea claro e intercultural.

4) En el caso de existir un conflicto de competencia entre jurisdicciones, debería llevarse a cabo una coordinación pronta y adecuada que haga posible un diálogo intercultural basado en la igualdad y respeto entre culturas, con el objetivo de garantizar su convivencia, transformar sus relaciones y estructuras sociales. 
Por otro lado, al analizar los elementos que conforman algunos sistemas jurídicos indígenas en México, se llegó a la conclusión de que éstos obedecen a su propia cosmovisión, principios y tradiciones. Por lo tanto, éstos deben ser respetados, ya que fueron construidos a partir de su identidad cultural, diferencias históricas y contextos sociales propios. Además de ser idóneos para restaurar la armonía y el tejido social de su comunidad.

Intentar asimilarlos, encuadrarlos o pretender que sus características sean las mismas que tiene el debido proceso del sistema jurídico estatal, violaría sus derechos constitucionales y convencionales a la libre determinación y a la autonomía, además iría en contra de los principios que sustentan un Estado pluricultural como lo es México.

Asimismo, en materia penal es un progreso que los sistemas jurídicos indígenas sean reconocidos en el nuevo CNPP; sin embargo, dicho avance resulta insuficiente por los siguientes motivos:

1) Establece requisitos desproporcionales a los sistemas jurídicos indígenas para que puedan resolver casos en la materia.

2) Es omiso en señalar procedimientos de coordinación o diálogos interculturales entre jurisdicciones, para aquellos casos en donde se alegue que la resolución de un sistema jurídico indígena ha violado algún derecho humano.

3) Por último, al restringir la competencia de los sistemas jurídicos indígenas respecto a delitos que prevén prisión preventiva oficiosa, obliga a las personas indígenas a someterse a la jurisdicción estatal, en la cual continúan sufriendo violaciones a sus derechos humanos y en la mayoría de los casos se encuentran privadas de la libertad por dichas inconsistencias.

Es claro que los derechos a la libre determinación y a la autonomía de los pueblos indígenas no nacieron para limitarse a quedar enunciados en constituciones, instrumentos internacionales y leyes. Por lo tanto, el derecho que tienen de mantener sus propios sistemas jurídicos debe respetarse por las autoridades estatales sin cuestionar su idoneidad, validez o legitimidad.

Para lograrlo, es necesario que se impulsen nuevas formas de relacionarse entre seres humanos, se reconozcan las diferencias históricas presentes en la sociedad y exista la apertura a escuchar y aprender de otras 
realidades. Sólo de esta forma se podrá erradicar la discriminación y subordinación histórica que han sufrido los pueblos indígenas en México, así como la negación de sus derechos.

Finalmente, resulta esencial comprender y aceptar que existen otras formas de brindar justicia que, a pesar de parecer muy diferentes a las nuestras, son igual de válidas y legítimas. Pues tal como lo ha señalado de forma acertada el reconocido sociólogo Boaventura de Sousa Santos, los sistemas jurídicos indígenas son "todo un sistema de territorios, de autogobierno, de cosmovisiones propias. Tienen una historia muy larga y una memoria igualmente bastante prolongada, constituida por mucho sufrimiento, pero también por muchísima resistencia hasta el presente" (de Sousa 2012, 22).

\section{BIBLIOGRAFÍA}

Libros y documentos académicos

ARAGÓn, Orlando y COLOR, Marycarmen. 2013. "Comentario al artículo 2o. constitucional”. Ferrer MAC-Gregor, Eduardo, CaballeRO OchOA, José Luis y SteIner, Cristian (coords.). Derechos humanos en la Constitución. Comentarios de jurisprudencia constitucional e interamericana. México. SCJN. UNAM: Instituto de Investigaciones Jurídicas. Fundación Konrad Adenauer.

ARAGÓN, Orlando. 2007. Indigenismo, movimientos y derechos indígenas en México: la reforma del artículo 4 constitucional de 1992. Morelia. Universidad michoacana de San Nicolas de Hidalgo.

BAZurco, Martín y Exen, José. 2012. "Bolivia: justicia indígenas en tiempos de plurinacionalidad". Sousa SANTOS, Boaventura de y ExENI, José (eds.). Fusticia indígena, plurinacionalidad e interculturales en Bolivia. Ecuador. Fundación Rosa Luxemburg/Abya-Yala.

FIX-Zamudio, Hector. 1989. "Debido proceso legal". Diccionario Jurídico Mexicano. México. Porrúa- UNAM.

GARCía MÁYNez, Eduardo. 2002. Introducción al estudio del derecho. 53a. ed. México. Porrúa.

GARCía RAMíREz, Sergio. 2012. El debido proceso: criterios de la jurisprudencia interamericana. México. Porrúa. 
García Ramírez, Sergio. 2018. El procedimiento penal: Constitución y Código Nacional. México. Porrúa-UNAM: Instituto de Investigaciones Jurídicas.

Gómez Colomer, Juan-Luis. 2015. "Prologo". Moreno Hernández, Moisés y Ontiveros Alonso, Miguel (coords.). Comentarios al Código Nacional de Procedimientos Penales. México. UBIJUS.

Robles ZAMARRIPA, José Ricardo. 2015. "Una mirada a los derechos humanos desde la interculturalidad y los diálogos interculturales: un punto de partida hacia la igualdad profunda". Revista del Posgrado en Derecho de la UNAM. Nueva Época 3.

RODRÍGUEZ, Jorge Luis. 2015. "Sistemas jurídicos". FABRA ZAMORA, Jorge Luis y RODRÍGUEz BLANCO, Verónica (eds.). Enciclopedia de Filosofia y Teoría del Derecho, 2 vols. México. UNAM: Instituto de Investigaciones.

LÓPEZ SÁNCHEZ, Javier. 2018. "El sentipensar indígena y su justicia”. LÓPEZ BÁRCENAS, Francisco (coord.). El pensamiento indígena contemporáneo. México. SCJN.

LÓPEz SARABIA, Tomás. 2018. "El ejercicio del pluralismo jurídico en el sistema jurídico mexicano". LÓPEz BÁRCENAS, Francisco (coord.). El pensamiento indígena contemporáneo. México. SGJN.

MEdina Quiroga, Cecilia. 2003. La Convención Americana: teoría y jurisprudencia. Vida, integridad personal, libertad persona, debido proceso y recurso judicial. Chile. Facultad de Derecho de la Universidad de Chile. Centro de Derechos Humanos.

Mendía Soto, Honorio. 2018. "La justicia oral y comunal o’dam: un análisis desde los principios de vida y directrices jurídicos". LÓPEZ BÁRGENAS, Francisco (coord.). El pensamiento indígena contemporáneo. México. SCJN.

MuÑoz de la GruZ, Maximino. 2018. "Justicia indígena Wizarika”. LÓPEZ BÁRCENAS, Francisco (coord.). El pensamiento indígena contemporáneo. México. SCJN.

Sousa Santos, Boaventura de. 2012. "Cuando los excluidos tienen derecho: justicia indígena, plurinacionalidad e interculturalidad". Boaventura de Sousa Santos y Exeni, José. Fusticia indigena, plurinacionalidad e interculturales en Bolivia. Ecuador. Fundación Rosa Luxemburg/Abya-Yala. 
Sousa Santos, Boaventura de. 2014. Derechos humanos, democracia y desarrollo. trad. de Carlos F. Morales de Setién Ravina. Colombia. Colección de Justicia.

Suprema Corte de Justicia de la Nación. 2013. Protocolo de actuación para quienes imparten justicia en casos que involucren derechos de personas, comunidades y pueblo indígenas. México. SCJN.

SIERRA, María Teresa. 2005. "Derecho indígena y acceso a la justicia en México: perspectivas desde la interlegalidad". Revista IIDH 41.

SOlANO GONZÁLEZ, Edgar. 2004. "La jurisdicción especial indígena ante la corte constitucional”. ORDÓÑEz CifuenTES, José Emilio Rolando (coord.). La construcción del Estado nacional: democracia, justicia, paz y Estado de derecho. Xll Fornadas Lascasianas. México. UNAM: Instituto de Investigaciones Jurídicas.

SiRvent, Consuelo. 2006. Sistemas jurídicos contemporáneos. 8a. ed. México. Porrúa.

VÁsquez Gutiérrez, Juan Pablo. 2013. "Multiculturalismo y diálogo intercultural". IBERO, Revista de la Universidad Iberoamericana 24.

WALSH, Catherin. 2009. Interculturalidad, Estado, sociedad. Luchas (de)coloniales de nuestra época. Ecuador. Universidad Andina Simón Bolívar y Ediciones Abya-Yala.

WALSH, Catherine. 2019. "Interculturalidad crítica y educación intercultural". Construyendo interculturalidad crítica. La Paz. Instituto Internacional de Integración del Convenio Andrés Bello.

Legislación nacional

Constitución Política de los Estados Unidos Mexicanos.

Constitución de Aguascalientes.

Constitución de Baja California.

Constitución de la Ciudad de México.

Constitución de Coahuila de Zaragoza.

Constitución de Guanajuato.

Constitución de Michoacán de Ocampo.

Constitución de Nayarit.

Constitución de Nuevo León.

Constitución de Tamaulipas.

Constitución de Yucatán.

Esta obra está bajo una Licencia Creative Commons

Atribución-NoComercial-SinDerivar 4.0 Internacional, IIJ-UNAM.

Boletín Mexicano de Derecho Comparado, núm. 158, mayo-agosto de 2020, pp. 619-650. 
Constitución de Zacatecas.

Código Nacional de Procedimientos Penales.

Ley Orgánica del Poder Judicial del Estado de Yucatán.

Ley de Derechos y Cultura indígenas del Estado de Chiapas.

Ley Reglamentaria del artículo 9 de la Constitución Política del Estado de San Luis Potosí, sobre los Derechos y la Cultura Indígena.

Decisiones de tribunales nacionales mexicanos

Amparo en revisión 123/2002, 4 de octubre de 2002. Suprema Corte de Justicia de la Nación. Segunda Sala.

Tribunal Electoral del Poder Judicial de la Federación. Juicio para la protección de los derechos político-electorales del ciudadano. Expediente SUP-JDC-9167/2011, 2 de noviembre de 2011.

Legislación y decisiones de tribunales nacionales

Tribunal Constitucional Plurinacional de Bolivia, Sentencia Constitucional Plurinacional 0234/2016-S3, 19 de febrero de 2016.

Corte Constitucional de Colombia, Sentencia 7-349/96, 8 de agosto de 1996.

Corte Constitucional de Colombia, Sentencia T-523/97, 1997.

Tribunal Constitucional del Ecuador, Sentencia N 113-14-SEP-CG Caso N. 0731-10-EP, 2014.

\section{Documentos internacionales}

Sistema universal de protección de derechos humanos (ONU)

Organización Internacional del Trabajo (OIT), Convenio No. 169 sobre Pueblos Indígenas y Tribales, 1989.

Naciones Unidas, Pacto Internacional de Derechos Civiles y Políticos, 1966.

Naciones Unidas, Pacto Internacional de Derechos Económicos, Sociales y Culturales, 1966. 


\section{Declaraciones internacionales}

Naciones Unidas, Declaración de las Naciones Unidas sobre Derechos de los Pueblos Indígenas, 2007.

Consejo de Derechos Humanos de las Naciones Unidas. 2003. Informe del Relator Especial de las Naciones Unidas sobre la situación de los derechos humanos y las libertades fundamentales de los indígenas, Sr. Rodolfo Stavenhagen, Misión a México, E/CN.4/2004/80.

Consejo de Derechos Humanos de las Naciones Unidas. 2013. Acceso a la justicia en la promoción y protección de los derechos de los pueblos indígenas, A/HRC/EMRIP/2013/2.

Consejo de Derechos Humanos de las Naciones Unidas. 2015. Informe de la Relatora Especial del Consejo de Derechos Humanos sobre los derechos de los pueblos indígenas relativo a las repercusiones de las inversiones internacionales y el libre comercio sobre los derechos humanos de los pueblos indígenas, Doc. ONU A/70/301/.

Consejo de Derechos Humanos de las Naciones Unidas. 2017. Informe sobre la situación de los derechos de los pueblos indígenas en México.

Consejo de Derechos Humanos de las Naciones Unidas. 2018. Informe de la Relatora Especial del Consejo de Derechos Humanos sobre los derechos de los pueblos indígenas, los pueblos indígenas y el autogobierno, Doc. A/73/17.

Consejo de Derechos Humanos de las Naciones Unidas. 2018. Presentación de la Relatora Especial de las Naciones Unidas sobre los derechos de los pueblos indígenas Victoria Tauli-Corpuz, Ciudad de México.

Consejo Económico y Social de las Naciones Unidas. 2010. Foro Permanente para las Cuestiones Indígenas. Pueblos Indígenas: desarrollo con cultura e identidad a la luz de la Declaración de las Naciones Unidas sobre los derechos de los pueblos indígenas, E/C.19/2010/17.

Consejo Económico y Social de las Naciones Unidas. 2003. Informe del Relator Especial sobre la situación de los derechos humanos y las libertades fundamentales de los indígenas, Misión a México, E/ GN.4/2004/80/Add.2.

Oficina del Alto Comisionado de las Naciones Unidas para los Derechos Humanos. 2008. El reconocimiento legal y vigencia de los Sistemas Normativos Indígenas en México. 
Organización de los Estados Americanos. 1969. Convención Americana de Derechos Humanos.

Organización de los Estados Americanos. 2016. Declaración Americana sobre los Derechos de los Pueblos Indígenas, AG//RES.2888 (XLVI$\mathrm{O} / 16)$.

Unión Africana. 1981. Carta Africana sobre Derechos Humanos y de los Pueblos.

Comisión Interamericana de Derechos Humanos. 2015. Situación de derechos humanos en México, OEA/Ser.L/V/II Doc.44/15.

\section{Casos contenciosos}

Corte IDH, Caso Tribunal Constitucional vs. Perú, Fondo, Reparaciones y costas, sentencia del 31 de enero de 2001, serie C, núm. 71.

Corte IDH, Caso Ivcher Bronstein vs. Perú, Fondo, Reparaciones y costas, sentencia del 6 de febrero de 2001, serie C, núm. 74 .

Corte IDH, Caso Yatama vs. Nicaragua, Excepciones preliminares, Fondo, reparaciones y costas, sentencia del 23 de junio de 2005, serie C, núm. 127.

Corte IDH, Caso Comunidad Indígena Xákmok Kásek vs. Paraguay, Fondo, reparaciones y costas, sentencia del 24 de agosto de 2010, serie C, núm. 214.

\section{Opiniones consultivas}

Corte IDH. 1987. Garantías Judiciales en Estados de Emergencia (artículos 27.2, 25 y 8 de la Convención Americana sobre Derechos Humanos). Opinión Consultiva OG-9/87, serie A, núm. 9.

Votos sobre los casos

Voto concurrente razonado del juez Sergio García Ramírez a la OC16/99 sobre El derecho a la Información sobre la Asistencia Consular en el Marco de las Garantías del Debido Proceso Legal, del 1o. de octubre de 1999, serie A, núm. 16. 


\section{Otros documentos}

Castillo García, Gustavo. 2017. "Disculpa pública de PGR a tres indígenas detenidas injustamente". La fornada. https://elpais.com/internacio nal/2017/02/21/mexico/1487681298_217747.html.

Comisión Nacional de Derechos Humanos. 2018. "Informe anual de actividades 2018: personas indígenas en reclusión". http://informe.cndh.org. $m x /$ menu. aspx:id $=40097$.

Colmenares, Ricardo. 2006. "El derecho consuetudinario indígena en Centro y Sur de América: el caso Venezuela". Frónesis 3(13).

Centro Prodh, Alberta Alcántara y Teresa González. http://centroprodh.org. $m x /$ casos-3/alberta-alcantara-y-teresa-gonzalez/.

Fondo para el Desarrollo de los Pueblos Indígenas de América Latina y el Caribe. 2019. Más de 8 mil indígenas en la cárcel por falta de traductores en México. https://wrerefilac.org/wp/comunicacion/actualidad-indigena/mas-de8-mil-indigenas-en-la-carcel-por-falta-de-traductores-en-mexico/.

García, Jacobo. 2017. "No sólo queremos perdón, exigimos respeto como indígenas", El País. https://elpais.com/internacional/2017/02/21/ mexico/1487681298_217747.html.

INPI-INALI. Atlas de los pueblos Indígenas en México. http://atlas.cdi.gob.mx/.

ORdóñEz Cifuentes, José Emilio Rolando. 2008. "Legalidad y legitimidad del sistema jurídico indígena en el marco del pluralismo jurídico”. Ferrer MaG-Gregor, Eduardo y ZALDÍvar Lelo de LARREA, Arturo (coords.). La ciencia del derecho procesal constitucional, Estudios en homenaje a Héctor Fix-Zamudio en sus cincuenta años como invstigador del derecho, t. XII: Ministerio Público, contencioso administrativo y actividad jurídica. México. UNAM: Instituto de Investigaciones Jurídicas.

SAÚl, Lilia y Rosario AvendaÑo, Olga. 2017. "México tiene 8,000 indígenas en prisión sin condena". Animal Político y Univisión. https://wrwe. animalpolitico.com/2017/04/mexico-8000-indigenas-prision-sin-condena/.

SHWANT DURÁN, John. 2005. "La costumbre jurídica de los pueblos mayas". Revista IIDH. http://wrwe.corteidh.or.cr/tablas/R08062-10.pdf. 